DOI: 10.26699/jnk.v1i2.ART.p135-139

This is an Open Access article under the CC BY-SA license (http://creativecommons.org/licenses/by-sa/4.0/)

\title{
STATUS MENTAL LANSIA DI PSLU TULUNGAGUNG
}

\author{
(Oldest Mental Status In PSLU Tulungagung)
}

\author{
Nopia Riana Dewi \\ Poltekkes Kemenkes Malang, J1 Besar Ijen No 77C Malang \\ Email: nopia_riana@ymail.com
}

\begin{abstract}
Old age is the final stage of the human life cycle and will inevitably be experienced by every individual, who will undergo physical and mental changes. The purpose of this study was to describe the mental status of the elderly. Method: Research design was descriptive study. The population in this study is 80 elders who live in PSLU Tulungagung in March 2014, Sample were 45 elderly by using purposive sampling technique. The data collected by using a questionnaire MMSE at May $18^{\text {th }}$ until 19 $9^{\text {th }}$, 2014. Results: The result showed that $53.3 \%$ no cognitive impairment, $20 \%$ and cognitive impairment was $26.7 \%$ experiencing severe cognitive impairment. Discussion: It is expected that the results of this study, health workers improve activities that are motivating and supporting the elderly in dealing with elderly dementia or memory to support the mental status of the elders.
\end{abstract}

Keywords: Mental Status, Elders

Angka harapan hidup manusia Indonesia semakin meningkat sejalan dengan meningkatnya taraf hidup dan pelayanan kesehatan. Kondisi ini membuat populasi orang berusia lanjut di Indonesia semakin tinggi (Wirakusumah, 2000:1). Secara umum proses menua didefinisikan sebagai perubahan yang terkait waktu, bersifat universal, intrinsic, progresif, dan detrimental. Proses menua antar individu dan antar organ tubuh tidaklah sama (Setiati, 2000:6). Kepandaian menyiasati berbagai serangan yang melemahkan kondisi tubuh, seperti berbagai perubahan fisik dan mental juga adanya berbagai penyakit merupakan kunci kebahagiaan lansia (Wirakusumah, 2000:1). Kesejahteraan mental dan kesejahteraan emosional adalah sebagai penting dalam usia yang lebih tua pada waktu lain dalam hidup. Yang paling umum gangguan neuropsikiatri pada kelompok usia ini adalah demensia dan depresi.

Usia lanjut adalah tahap akhir dari siklus hidup manusia, merupakan bagian dari proses kehidupan yang tak dapat dihindarkan dan akan dialami oleh setiap individu. Pada tahap ini individu mengalami banyak perubahan fisik maupun mental, khususnya kemunduran dalam berbagai fungsi dan kemampuan yang pernah dimiliki (Dharmono,
2000:157). Sedangkan menurut Darajat (1996:4) sehat mental adalah pengetahuan atau perbuatan yang bertujuan untuk mengembangkan dan memanfaatkan segala potensi, bakat, dan pembawaan yang ada semaksimal mungkin, sehingga membawa kepada kebahagiaan diri dan orang lain.

Dari studi pendahuluan melalui observasi pada tanggal 14 November 2013, diketahui bahwa lansia kurang melakukan aktivitas fisik, aktivitas mental dan sosial, serta kesehatan lansia yang menurun dan kurangnya partisipasi akan dukungan keluarga sendiri merupakan faktor dari pencapaian dari kesehatan mental. Setelah dilakukan wawancara dengan menggunakan MMSE (Mini Mental Status Exam) dari 10 orang lansia di Panti Sosial Lanjut Usia (PSLU) Kabupaten Tulungagung, diperoleh data yaitu 5 orang lansia mengalami gangguan Aspek Kognitif berat (pada Aspek Kognitif Orientasi, Perhatian dan Kalkulasi, serta Bahasa), 3 orang lansia mengalami gangguan Aspek Kognitif Sedang (pada Aspek Kognitif Orientasi, Perhatian dan Kalkulasi), sedangkan 2 orang lansia tidak mengalami gangguan Aspek Kognitif.

Rumusan masalahnya yaitu bagaimanakah gambaran status mental lansia 
di Panti Sosial Lanjut Usia (PSLU) Tulungagung?. Tujuan Penelitian ini adalah menggambarkan status mental lansia di Panti Sosial Lanjut Usia (PSLU) Tulungagung.

\section{BAHAN DAN METODE}

Desain penelitian yang digunakan adalah deskriptif. Dalam hal ini yang diteliti adalah gambaran status mental lansia di PSLU Tulungagung. Populasi dalam penelitian ini adalah lansia yang tinggal di PSLU Tulungagung pada bulan Maret 2014 sebanyak 80 lansia di PSLU Tulungagung, sampel pada penelitian ini adalah 45 lansia dengan kriteria inklusi dalam penelitian ini adalah:a) Lansia yang berumur $\geq 45$ tahun, b)Lansia yang kooperatif untuk menjadi responden, c) Lansia yang tinggal di PSLU Tulungagung.

Pengambilan sampel dilakukan dengan teknik purposive sampling. Pengumpulan data dilakukan dengan menggunakan kuesioner MMSE (Mini Mental Status Exam) dari Folstein M.F. et al, 1975 dalam (Lueckenotte,1997). Penelitian dilaksanakan di PSLU Tulungagung pada tanggal 18-19 Mei 2014. Data disajikan dalam bentuk tabel dan dijelaskan secara deskriptif dengan menggunakan narasi.

\section{HASIL PENELITIAN}

Karakteristik Lansia di PSLU Tulungagung Mei 2014.

Tabel 1. Karakteristik Lansia di PSLU Tulungagung Mei 2014

\begin{tabular}{llcc}
\hline No & Karakteristik & f & \% \\
\hline 1 & Umur & & \\
& - 45-59 tahun & 2 & 4 \\
& - 60-74 tahun & 21 & 47 \\
& - 75-90 tahun & 18 & 40 \\
& - >90 tahun & 4 & 9 \\
2 & Jenis Kelamin & & \\
& - Laki-laki & 15 & 33 \\
& - Perempuan & 30 & 67 \\
3 & Pekerjaan Dahulu & & \\
& - Pensiunan & 1 & 2 \\
& - Pegawai Swasta & 10 & 22 \\
& - Petani & 10 & 22 \\
\hline
\end{tabular}

\begin{tabular}{|c|c|c|c|}
\hline No & Karakteristik & $\mathbf{f}$ & $\%$ \\
\hline & - Wiraswasta & 18 & 40 \\
\hline & - Lain-lain & 6 & 14 \\
\hline \multirow[t]{6}{*}{4} & Pendidikan & & \\
\hline & Terakhir & & \\
\hline & - Lain-lain & 14 & 31 \\
\hline & $-\mathrm{SD}$ & 22 & 49 \\
\hline & - SMP & 4 & 9 \\
\hline & - SMA & 5 & 11 \\
\hline \multirow[t]{5}{*}{5} & $\begin{array}{l}\text { Yang membesuk di } \\
\text { PSLU }\end{array}$ & & \\
\hline & - Tidak ada & 14 & 31 \\
\hline & - Tetangga & 3 & 7 \\
\hline & $\begin{array}{l}\text { - Anggota keluarga } \\
\text { lain }\end{array}$ & 17 & 38 \\
\hline & - Anak & 11 & 24 \\
\hline \multirow[t]{3}{*}{6} & $\begin{array}{l}\text { Keinginan tinggal } \\
\text { di PSLU }\end{array}$ & & \\
\hline & - Keinginan sendiri & 18 & 40 \\
\hline & $\begin{array}{l}\text { - Keinginan } \\
\text { keluarga }\end{array}$ & 27 & 60 \\
\hline 7 & $\begin{array}{l}\text { Lama tinggal (rata- } \\
\text { rata) }=38,15\end{array}$ & 45 & 100 \\
\hline \multirow[t]{6}{*}{8} & Frekuensi & & \\
\hline & kunjungan keluarga & & \\
\hline & - Tidak pernah & 15 & 33 \\
\hline & $\begin{array}{l}\text { - Setiap tahun } \\
\text { sekali }\end{array}$ & 10 & 22 \\
\hline & $\begin{array}{l}\text { - Setiap/beberapa } \\
\text { bulan sekali }\end{array}$ & 18 & 40 \\
\hline & - Setiap minggu & 2 & 5 \\
\hline \multirow[t]{4}{*}{9} & $\begin{array}{l}\text { Jenis Aktifitas di } \\
\text { PSLU }\end{array}$ & & \\
\hline & $\begin{array}{l}\text { - Tidak melakukan } \\
\text { aktifitas }\end{array}$ & 3 & 7 \\
\hline & $\begin{array}{ll}\text { - Salah } & \text { satu } \\
\text { aktifitas } & \end{array}$ & 14 & 31 \\
\hline & - Semua aktifitas & 28 & 62 \\
\hline
\end{tabular}

Tabel 2. Status Mental Lansia di PSLU Tuluangagung Mei 2014

\begin{tabular}{llcc}
\hline No & \multicolumn{1}{c}{ Status Mental } & f & \% \\
\hline 1 & Tidak gangguan kognitif & 24 & 53,3 \\
2 & Gangguan kognitif & 9 & 20 \\
& sedang & & \\
3 & Gangguan kognitif berat & 12 & 26,7 \\
\hline
\end{tabular}

Tabel 3 Tabulasi silang antara pendidikan terakhir dengan status mental lansia di PSLU Tulungagung, Mei 2014 


\begin{tabular}{llcccccc}
\hline & & \multicolumn{5}{c}{ Status Mental } \\
\cline { 2 - 8 } No. & $\begin{array}{c}\text { Pendidikan } \\
\text { terakhir }\end{array}$ & \multicolumn{2}{c}{$\begin{array}{c}\text { Tidak ada } \\
\text { gangguan }\end{array}$} & \multicolumn{2}{c}{ Gangguan sedang } & Gangguan berat \\
\cline { 3 - 8 } & & $\mathbf{f}$ & $\mathbf{\%}$ & $\mathbf{f}$ & $\mathbf{\%}$ & $\mathbf{f}$ & \% \\
\hline 1. & SD & 13 & 28,9 & 3 & 6,7 & 6 & 13,3 \\
2. & SMP & 1 & 2,2 & 2 & 4,4 & 1 & 2,2 \\
3. & SMA & 5 & 11,1 & 0 & 0 & 0 & 11,1 \\
4. & Lain - lain & 5 & 11,1 & 4 & 8,9 & 5 & 11,1 \\
\hline
\end{tabular}

Tabel 4 Tabulasi silang antara umur dengan status mental lansia di PSLU Tulungagung, Mei 2014.

\begin{tabular}{|c|c|c|c|c|c|c|c|}
\hline \multirow{3}{*}{ No } & \multirow{3}{*}{ Umur } & \multicolumn{6}{|c|}{ Status Mental } \\
\hline & & \multicolumn{2}{|c|}{$\begin{array}{l}\text { Tidak ada } \\
\text { gangguan }\end{array}$} & \multicolumn{2}{|c|}{ Gangguan sedang } & \multicolumn{2}{|c|}{ Gangguan berat } \\
\hline & & f & $\%$ & $\mathbf{f}$ & $\%$ & $\mathbf{f}$ & $\%$ \\
\hline 1. & $45-59$ tahun & 0 & 0 & 0 & 0 & 2 & 4,4 \\
\hline 2. & $60-74$ tahun & 13 & 28,9 & 3 & 6,7 & 5 & 11,1 \\
\hline 3. & $75-90$ tahun & 9 & 20 & 6 & 13,3 & 3 & 6,7 \\
\hline 4. & $>90$ tahun & 2 & 4,4 & 0 & 0 & 2 & 4,4 \\
\hline
\end{tabular}

Tabel 5 Tabulasi silang antara jenis aktivitas kegiatan lansia dengan status mental lansia di PSLU Tulungagung, Mei 2014.

\begin{tabular}{|c|c|c|c|c|c|c|c|}
\hline \multirow{3}{*}{ No } & \multirow{3}{*}{$\begin{array}{l}\text { Jenis aktivitas } \\
\text { kegiatan }\end{array}$} & \multicolumn{6}{|c|}{ Status Mental } \\
\hline & & \multicolumn{2}{|c|}{$\begin{array}{l}\text { Tidak ada } \\
\text { gangguan }\end{array}$} & \multicolumn{2}{|c|}{$\begin{array}{l}\text { Gangguan } \\
\text { sedang }\end{array}$} & \multicolumn{2}{|c|}{ Gangguan berat } \\
\hline & & $\mathbf{f}$ & $\%$ & $\mathbf{f}$ & $\%$ & f & $\%$ \\
\hline 1. & Dilakukan semua & 17 & 37,8 & 6 & 13,3 & 5 & 11,1 \\
\hline 2. & $\begin{array}{l}\text { Hanya beberapa } \\
\text { kegiatan }\end{array}$ & 7 & 15,6 & 2 & 4,4 & 5 & 11,1 \\
\hline 3. & Lain - lain & 0 & 0 & 1 & 2,2 & 2 & 4,4 \\
\hline
\end{tabular}

Berdasarkan hasil penelitian didapatkan data gambaran status mental lansia sebesar 53,3\% (24 lansia) tidak ada gangguan kognitif, 20\% (9 lansia) gangguan kognitif sedang dan 26,7\% (12 lansia) mengalami gangguan kognitif berat. Menurut Jean Piaget dalam (Kaplan, Sadock dan Grebb, 1997:232-233) Membuat jawaban palsu dari pengkajian status mental yang tidak disadari jika daya ingat terganggu adalah paling dekat berhubungan dengan gangguan kognitif. Menurut peneliti, banyak faktor yang mempengaruhi akan gangguan kognitif kepada lansia. Faktor pertama, yaitu tingkat pendidikan sangat mempengaruhi status mental lansia. Dari penelitian yang telah dilakukan hasil dari tabulasi silang pendidikan terakhir dengan status mental lansia dalam gambaran status mental lansia di PSLU Tulungagung bahwa kategori status mental tidak ada gangguan kognitif yaitu 28,9\% (13 lansia) berpendidikan terakhir SD dan $11,1 \%$ (5 lansia) berpendidikan terakhir lain-lain atau tidak sekolah. Kategori status mental dengan gangguan kognitif sedang yaitu $6,7 \%$ (3 lansia) berpendidikan terakhir $\mathrm{SD}$, dan $8,9 \%$ (4 lansia) berpendidikan terakhir lain-lain atau tidak sekolah. Sedangkan kategori status mental dengan gangguan kognitif berat yaitu sejumlah $13,3 \%$ (6 lansia) berpendidikan terakhir SD, dan $11,1 \%$ (5 lansia) berpendidikan terakhir lain-lain atau tidak sekolah. Menurut Gallo, Reichel, Andersen (1998:50-55) menegaskan bahwa hasil angka-angka instrumen pemeriksaan status mental menunjukkan tingkat pendidikan dari subjek. Nilai angka yang lebih rendah mungkin mengimplikasikan gangguan kognitif berat pada orang-orang dengan tingkat pendidikan 
rendah. Peneliti berpendapat bahwa pendidikan terakhir seorang lansia sangat berpengaruh pada status mental seorang lansia, dibuktikan dengan hasil jawaban parameter perhatian dan kalkulasi lansia didapatkan hasil lansia yang menjawab benar 28 , serta dalam parameter bahasa didapatkan skor terendah 14. Hal ini jelas dengan tingkat pendidikan dulunya didapatkan seorang lansia akan lebih mudah memahami dan menyerap informasi yang diperolehnya.

Faktor perubahan kognitif pada lansia kedua, yaitu umur/lanjut usia ( $>65$ tahun) ikut berpengaruh dalam status mental lansia. Hasil dari tabulasi silang umur dengan status mental lansia dalam gambaran status mental lansia di PSLU Tulungagung didapatkan hasil yaitu, kategori status mental tidak ada gangguan kognitif 28,9\% (13 lansia) berumur 60-74 tahun, 20\% (9 lansia) berumur 75-90 tahun dan 4,4\% (2 lansia) berumur $>90$ tahun. Kategori status mental dengan gangguan kognitif sedang didapatkan hasil yaitu, 6,7\% (3 lansia) berumur 60-74 tahun, sedangkan 13,3\% (6 lansia) berumur 75-90 tahun. Dan kategori status mental dengan gangguan kognitif berat didapatkan hasil yaitu, 11,1\% (5 lansia) berumur 60-74 tahun, sedangkan 6,7\% (3 lansia) berumur 75-90 tahun dan $4,4 \%$ (2 lansia) berumur $>90$ tahun. Menurut Gallo, Reichel, Andersen, (1998:50-55) individu usia menengah atau lansia tanpa kasus mungkin akan mengeluhkan terjadinya kesulitan memori; gejala-gejala memori mereka cocok dengan keadaan yang disebut pikun usia tua atau, akhir-akhir ini lebih cenderung disebut kerusakan memori berkenaan dengan usia atau penurunan kognitif berkenaan dengan proses penuaan. Peneliti berpendapat bahwa usia/umur sangat berpengaruh dalam perubahan kognitif (status mental) pada lansia, perubahan kognitif (status mental) yang sering dialami oleh lansia khususnya dikaitkan dengan pelupa atau pikun. Dibuktikan dalam parameter Orientasi bahwa skor yang diperoleh terendah 19, yaitu dalam kategori penyebutan tanggal. Sehingga, perlu diberikan motivasi kepada lansia untuk melakukan aktivitas.

Faktor selanjutnya adalah aktivitas fisik. Dari hasil tabulasi silang antara jenis aktivitas kegiatan dengan status mental lansia dalam gambaran status mental lansia di PSLU
Tulungagung, hasilnya bahwa kategori status mental tidak ada gangguan kognitif sebanyak 37,8\% (17 lansia) melakukan jenis aktivitas kegiatan dengan dilakukan semua, Selanjutnya untuk kategori status mental gangguan kognitif berat hasilnya $11,1 \%$ (5 lansia) melakukan jenis aktivitas kegiatan dilakukan semua, dan 4,4\% (2 lansia) melakukan jenis aktivitas kegiatan lain - lain. Menurut Lemon et al, 1972, dalam Lueckenotte, 2000 dalam (Subekti, 2012:8), menyatakan bahwa orang tua yang aktif secara sosial lebih cenderung menyesuaikan diri terhadap penuaan yang baik. Peneliti berpendapat bahwa jenis aktivitas kegiatan lansia sangatlah penting dalam kesejahteraan usia lanjut. Hal ini akan berkaitan dengan lansia yang tidak mendapat dukungan dari keluarganya maka juga akan mempengaruhi keaktifan dari lansia sendiri. Selain itu dibuktikan pada parameter bahasa, dimana lansia yang dapat mengikuti perintah sederhana memiliki skor 40 dari keseluruhan, yang berarti bahwa lansia masih mau untuk melakukan aktivitas walau hanya perintah aktivitas kecil.

Dalam penelitian, tabulasi silang yang membesuk lansia di PSLU Tulungagung dengan status mental lansia didapatkan hasil yaitu dalam kategori tidak ada gangguan 13,3\% (6 lansia) yang membesuk lansia di PSLU adalah anaknya, dan 13,3\% (6 lansia) yang membesuk lansia di PSLU adalah lainlain (tidak ada yang menjenguk). Sedangkan, untuk kategori gangguan kognitif berat 2,2\% (1 lansia) yang membesuk lansia di PSLU adalah anaknya, dan $11,1 \%$ (5 lansia) yang membesuk lansia adalah lain-lain (tidak ada yang menjenguk). Menurut Hogstel (2006:22-23) faktor pencapaian kesehatan mental lansia yang terakhir adalah dukungan sosial. Bahwa komponen penting yang lain dari masa tua yang sukses dan kesehatan mental adalah adanya sistem pendukung yang efektif. Peneliti berpendapat bahwa sumber dukungan sosial memang sangat menjadi komponen penting dalam tercapainya lansia yang suskes didalam masa tuanya. Oleh karena itu, dukungan sosial dari pemberi pelayanan kesehatan baik dari petugas di PSLU ataupun perawat praktik dan teman sesama lansia yang tinggal akan mencegah lansia dalam perubahan mentalnya. 


\section{SIMPULAN DAN SARAN Simpulan}

Sesuai dengan hasil penelitian dan pembahasan di PSLU Tulungagung untuk mengetahui gambaran status mental lansia dapat disimpulkan status mental lansia yaitu $53,3 \%$ tidak ada gangguan kognitif, 46,7\% mengalami gangguan kognitif sedang, dan berat. Dalam penelitian ini lansia yang mengalami gangguan kognitif sedang dan berat terdapat dalam kategori tabulasi silang antara lain; pendidikan terakhir SD, yang membesuk lain-lain (tidak ada yang membesuk), keinginan tinggal dari keluarga, jumlah kunjungan keluarga bahwa tidak pernah dilakukan kunjungan, dan jenis aktivitas yang dilakukan tidak semua dilakukan serta ada yang tidak melakukan aktivitas.

\section{Saran}

Saran yang dapat diberikan agar keluarga, petugas ataupun mahasiswa praktik bagi lansia di Panti Sosial Lanjut Usia (PSLU)dapat memberikan motivasi aktivitas serta dukungan terhadap lansia yang tidak mengalami gangguan kognitif dapat terus dapat dimotivasi untuk tetap melakukan aktivitas kegiatan khususnya bimbingan mental agar tidak mengarah ke gangguan kognitif. Kemudian, untuk lansia yang mengalami gangguan kognitif dapat untuk lebih diberikan motivasi baik dari petugas maupun mahasiswa praktik dalam pemberdayaan lansia, seperti; untuk melakukan aktivitas seperti bersih-bersih ruangan, membuat kerajinan contohnya membuat sapu/kemoceng, motivasi untuk menghadiri bimbingan mental contohnya pengajian.

\section{DAFTAR RUJUKAN}

Darmono, Surjo dan Setiati, Siti. 2000. Pedoman Pengelolaan Kesehatan Pasien Geriatri. Jakarta: Pusat Informasi dan Penerjemah Bagian
Ilmu Penyakit Dalam Fakultas Kedokteran Universitas Indonesia.

Darmojo, R. Boedhi dan Martono, H. Hadi. 1999. Buku Ajar Geriatri Ilmu Kesehatan Usia Lanjut. Jakarta: Fakultas Kedokteran Universitas Indonesia.

Darajat, Zakiah. 1996. Kesehatan Mental. Jakarta: PT Gunung Agung.

Gallo, Joseph J., Reichel, Wiliam dan Andersen, Lillian M. 1998. Buku Saku Gerontologi, Edisi 2. Jakarta: EGC.

Hogstel, Mildred O., dalam Stanley, Mickey dan Beare, Patricia G. 2006. Buku Ajar Keperawatan Gerontik Edisi 2. Jakarta: EGC.

Kushariyadi. 2011. Asuhan Keperawatan pada Klien Lanjut Usia. Jakarta: Salemba Medika.

Maslow dan Mittlemen 1963, dalam Notosoedirdjo, Moeljono dan Latipun. 2002. Kesehatan Mental, Konsep dan Penerapan. Malang: Universitas Muhammadiyah Malang.

Rasmun. 2001. Keperawatan Kesehatan Mental Psikiatri Terintegrasi Dengan Keluarga. Jakarta: Fajar Interpratama.

Stanley, Mickey \& Beare, Patricia G. 2006. Buku Ajar Keperawatan Gerontik Edisi 2. Jakarta: EGC.

Schneiders 1964, dalam Notosoedirdjo, Moeljono dan Latipun. 2002. Kesehatan Mental, Konsep dan Penerapan. Malang: Universitas Muhammadiyah Malang.

Subekti, Imam, Sugianto, Hariyanto, Tanto. 2012. Modul Pembelajaran Keperawatan Gerontik. Malang: Politeknik Kesehatan Kemenkes Malang.

Wirakusumah, Emma S. 2000. Tetap Bugar Di Usia Lanjut. Jakarta: Trubus Agriwiyata. 